\title{
Global energy and molecular interactions between Pazopanib, Axitinib and Sorafenib anticancer drugs with vascular endothelial growth factor
}

\author{
Kalu Kalu Igwe ${ }^{1 *}$, Okezie Victor Ikpeazu ${ }^{2}$ and Ifeanyi Edozie Otuokere ${ }^{3}$ \\ 1Department of Veterinary Biochemistry and Animal Production, Michael Okpara University of Agriculture, Umudike, \\ Nigeria. \\ ${ }^{2}$ Department of Biochemistry, Abia State University, Uturu, Nigeria. \\ ${ }^{3}$ Department of Chemistry, Michael Okpara University of Agriculture, Umudike, Nigeria. \\ ${ }^{\star}$ Corresponding author. Email: kkigwe191@gmail.com
}

Copyright (C) 2017 Igwe et al. This article remains permanently open access under the terms of the Creative Commons Attribution License 4.0, which permits unrestricted use, distribution, and reproduction in any medium, provided the original work is properly cited.

Received 21st July, 2017; Accepted 22nd August, 2017

\begin{abstract}
Pazopanib and axitinib are ATP-competitive inhibitors of the vascular endothelial growth factor receptor. They have shown to be effective and tolerable treatment options for patients with metastatic renal cell cancer and therefore have been used for the control of this disease. Sorafenib is a kinase inhibitor drug approved for the treatment of primary kidney cancer, advanced primary liver cancer, and radioactive iodine resistant advanced thyroid carcinoma. Global energy, binding sites and molecular interactions between pazopanib, sorafenib and axitinib anticancer drugs with vascular endothelial growth factor (VEGF) was probed to find the best binding energy. The structures of pazopanib, axitinib and sorafenib were drawn and constructed using window based program of Arguslab and ACDlab ChemSketch softwares. Docking studies were performed using the Patch dock and Firedock online software packages. The protein data bank (PDB) files of the crystal structure of VEGF were subjected to refinement protocols. The interactive docking method was carried out for all the conformers of each compound in the selected active site. The docked compound was assigned a score according to its fit in the ligand binding pocket (LBP) and its binding mode. The docked complexes were interpreted using Molecular Molegro viewer software. The best binding energy (minimum energy) is -19.15 $\mathrm{Kcal} / \mathrm{mol},-22.48 \mathrm{Kcal} / \mathrm{mol}$ and $-22.37 \mathrm{Kcal} / \mathrm{mol}$ for pozapanib, sorafenib and axitinid respectively. The negative value of the binding energy shows that pozapanib, sorafenib and axitinib can selectively inhibit VEGF.
\end{abstract}

Key words: Global energy, Pazopanib, Axitinib, Sorafenib, Vascular Endothelial Growth Factor.

\section{INTRODUCTION}

Pazopanib (trade name Votrient) is a potent and selective multi-targeted receptor tyrosine kinase inhibitor that blocks tumour growth and inhibits angiogenesis. It has been approved for renal cell carcinoma and soft tissue sarcoma by numerous regulatory administrations worldwide (Khurana et al., 2014; Verweij et al., 2013; Schöffski et al., 2012; Pick et al., 2012). It is a multikinase inhibitor and VEGFR being amongst the inhibited enzymes (Zivi et al., 2012). Laboratory anomalies include increased aspartate amino transferase, alanine aminotransferase and protein in the urine, oedema, hair loss or discolouration, taste changes, abdominal pain, hypertension, rash, fatigue and myelosuppression. Leucopenia, neutropenia, thrombocytopenia and lymhpoenia are also seen (Product Information Votrien, 2013). Axitinib (AG013736; trade name Inlyta) is a small molecule tyrosine kinase inhibitor developed by Pfizer. It has been shown to significantly inhibit growth of breast cancer in animal (xenograft) models (Wilmes et al., 2007) and has shown partial responses in clinical trials with renal cell carcinoma (RCC) (Rini et al., 2005) and several other tumour types (Rugo et al., 2005). Its primary mechanism of action is thought to be Vascular Endothelial Growth Factor receptor 1-3, c-KIT and 
A<smiles>Cc1ccc(Nc2nccc(N(C)c3ccc4c(C)n(C)nc4c3)n2)cc1S(N)(=O)=O</smiles>

Pazopanib
B<smiles>CNC(=O)c1ccccc1Sc1ccc2c(/C=C/c3ccccn3)n[nH]c2c1</smiles>

Axitinib
C<smiles>CNC(=O)c1cc(Oc2ccc(NC(=O)Nc3ccc(Cl)c(C(F)(F)F)c3)cc2)ccn1</smiles>

Sorafenib

Figure 1. Chemical structures.

PDGFR inhibition. This in turn enables it to inhibit angiogenesis (the formation of new blood vessels by tumours) (Escudier et al., 2007). Sorafenib (FDA Approves Nexavar 2007) is a kinase inhibitor drug approved for the treatment of primary kidney cancer (advanced renal cell carcinoma), advanced primary liver cancer (hepatocellular carcinoma), and radioactive iodine resistant advanced thyroid carcinoma. Sorafenid is a small inhibitor of several tyrosine protien kinase, such as VEGFR, PDGFR and Raf family kinases (Nexavar dosing, 2013; Smalley et al., 2008; Keating and Santoro, 2009). At the current time sorafenib is indicated as a treatment for advanced renal cell carcinoma (RCC), unresectable hepatocellular carcinomas (HCC) and thyriod cancer (FDA Approves Nexavar, 2007; Nexavar dosing, 2013). This study is designed to search the active sites, global energy and molecular interactions between pazopanib, axitinib and sorafenib anticancer drugs with VEGF. Chemical structures of pazopanib, axitinib and sorafenib are shown in Figure 1.

\section{MATERIALS AND METHODS}

The structures of pazopanib, axitinib and sorafenib were drawn and constructed using window based program of Arguslab (Thompson et al., 2007) and ACDlab ChemSketch (Advanced Chemistry Develoment, 2008) softwares. Docking studies were performed using the Patch dock and firedock online software packages (Mashiach et al., 2008; Andrusier et al., 2007). The protein data bank (PDB) files of the crystal structure of vascular endothelial growth factor (VEGF) refined to 1.93 A (Mashiach et al., 2008) resolution having PDB entry number 2VPF was downloaded from the protein data bank website. Regularization and optimization for protein and ligand were performed and the protein structure was subjected to a refinement protocol using Molegro Molecular viewer (Molegro Molecular Viewer, 2012).

Determination of the essential amino acid in binding

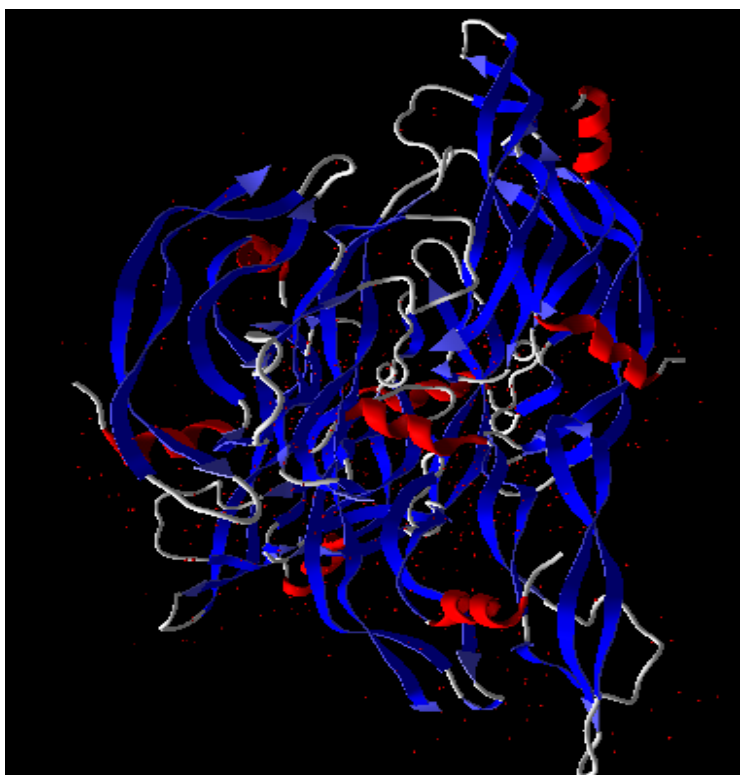

Figure 2. The crystal structure of vascular endothelial growth factor (VEGF) refined to $1.93 \mathrm{~A}$ resolution.

site was carried out. The interactive docking method was carried out for all the conformers of each compound in the selected active site. The docked compound was assigned a score according to its fit in the ligand binding pocket (LBP) and its binding mode. The docked complexes were interpreted using Molecular Molegro viewer software (Molegro Molecular Viewer, 2012).

\section{RESULTS AND DISCUSSION}

The crystal structure of VEGF refined to $1.93 \mathrm{~A}$ resolution is shown in Figure 2. Pazopanib, sorafenib and axitinib docked with VEGF are shown in Figures $3 a, 4 a$ and $5 a$ respectively. Interactions of pazopanib, sorafenib and axitinib with VEGF are presented in Figures 3b, $4 b$ and $5 b$ 


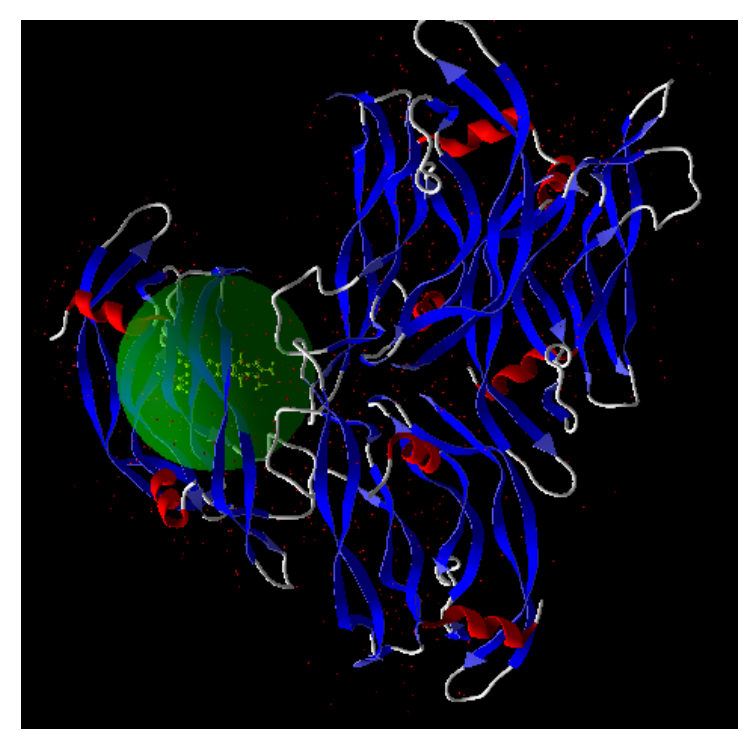

Figure 3a. Pazopanib docked with vascular endothelial growth factor (VEGF).

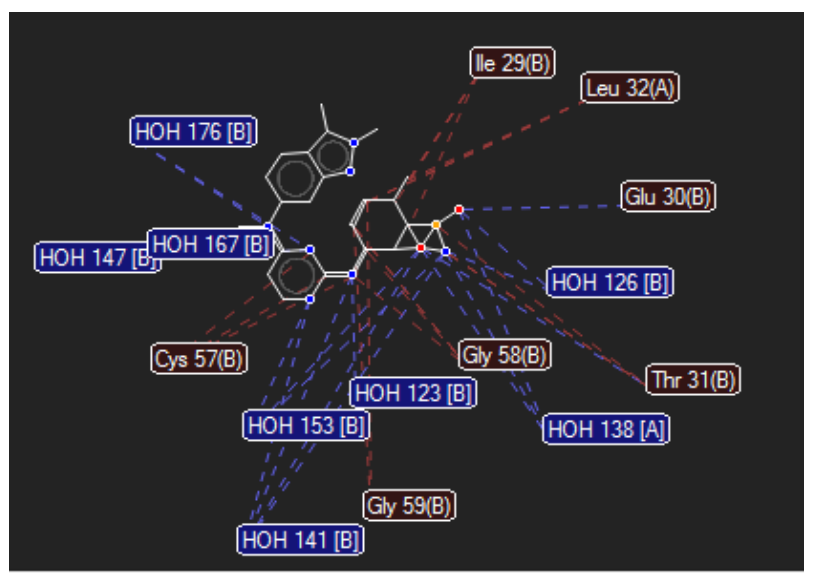

Figure 3b. Interactions of pazopanib with vascular endothelial growth factor (VEGF).

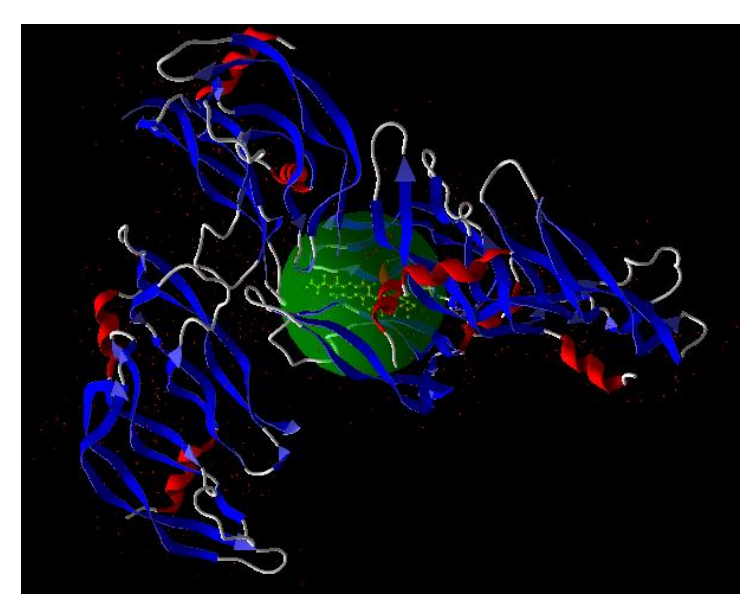

Figure 4a. Sorafenib docked with vascular endothelial growth factor (VEGF).

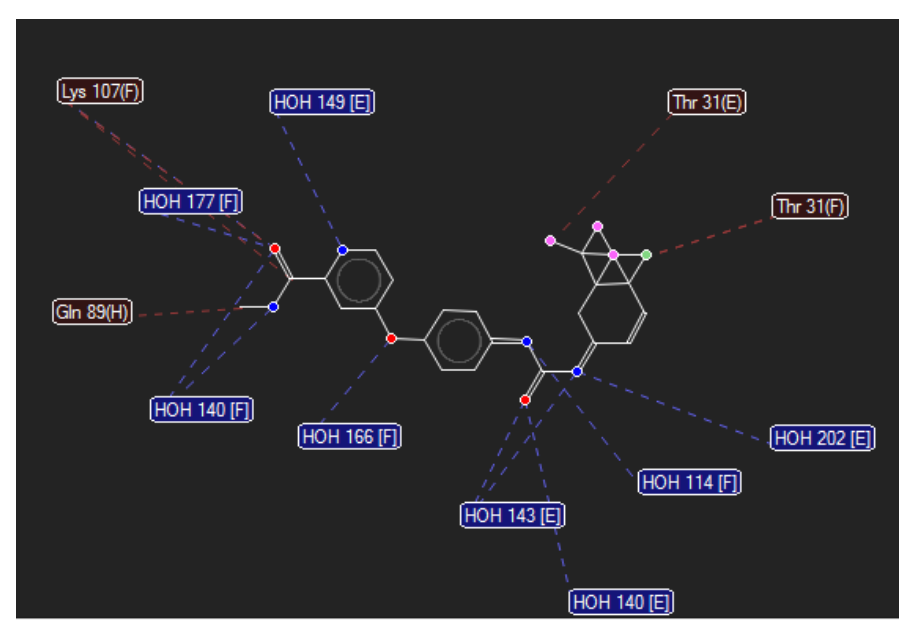

Figure $\mathbf{4 b}$. Interactions of sorafenib with vascular endothelial growth factor (VEGF).

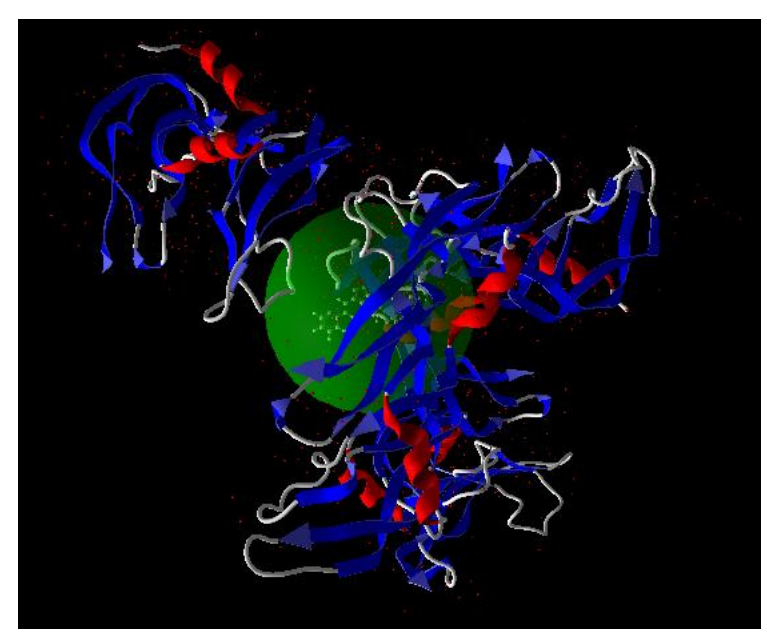

Figure 5a. Axitinib docked with vascular endothelial growth factor (VEGF).

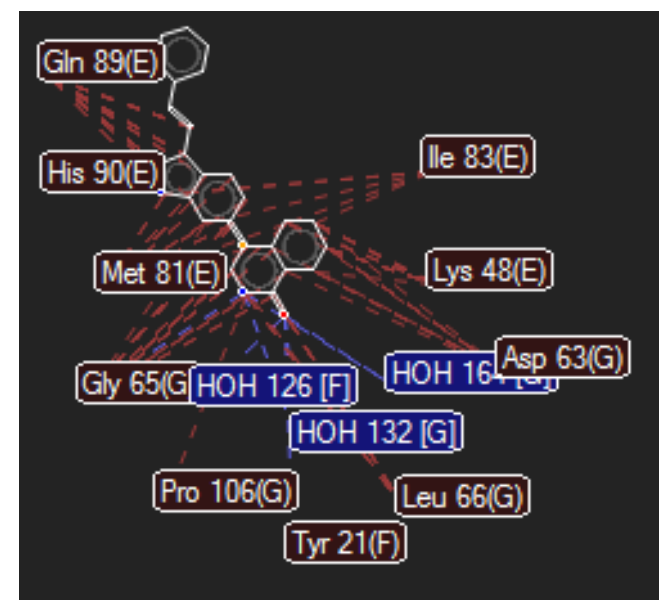

Figure 5b. Interactions of axitinib with vascular endothelial growth factor (VEGF). 
Table 1. Global energy predictions for pozapanib - vascular endothelial growth factor (VEGF) complex.

\begin{tabular}{lccccc}
\hline Rank & Solution Number & $\begin{array}{c}\text { Global Energy } \\
\text { Kcal/mol }\end{array}$ & $\begin{array}{c}\text { Attractive VdW } \\
\text { Kcal/mol }\end{array}$ & $\begin{array}{c}\text { Repulsive VdW } \\
\text { Kcal/mol }\end{array}$ & ACE Kcal/mol \\
\hline 1 & 7 & -19.15 & -8.11 & 7.14 & -9.59 \\
2 & 4 & -18.71 & -10.71 & 5.28 & -5.36 \\
3 & 10 & -5.14 & -5.51 & 0.29 & 0.22 \\
4 & 3 & -4.00 & -3.81 & 1.21 & -1.38 \\
5 & 2 & -2.00 & -0.70 & 0.00 & -1.86 \\
6 & 1 & 4.90 & -3.01 & 14.92 & -2.77 \\
7 & 6 & 46.63 & -16.00 & 115.33 & -16.14 \\
8 & 9 & 95.41 & -22.10 & 185.49 & -13.77 \\
9 & 8 & 239.64 & -19.67 & 371.93 & -19.14 \\
10 & 5 & 1959.18 & -22.25 & 2533.24 & -22.27 \\
\hline
\end{tabular}

Table 2. Global energy predictions for sorafenib - vascular endothelial growth factor (VEGF) complex.

\begin{tabular}{lccccc}
\hline Rank & Solution Number & $\begin{array}{c}\text { Global Energy } \\
\text { Kcal/mol }\end{array}$ & $\begin{array}{c}\text { Attractive VdW } \\
\text { Kcal/mol }\end{array}$ & $\begin{array}{c}\text { Repulsive VdW } \\
\text { Kcal/mol }\end{array}$ & ACE Kcal/mol \\
\hline 1 & 4 & -22.48 & -12.98 & 3.11 & -5.00 \\
2 & 5 & -8.06 & -7.30 & 0.26 & -0.52 \\
3 & 6 & -4.96 & -5.92 & 0.80 & -0.78 \\
4 & 10 & -2.31 & -9.42 & 14.29 & -0.93 \\
5 & 8 & -0.75 & -5.28 & 3.13 & 1.44 \\
6 & 7 & 1.89 & -3.67 & 1.76 & 2.79 \\
7 & 9 & 16.59 & -17.99 & 64.51 & -7.20 \\
8 & 2 & 604.69 & -15.20 & 796.81 & -7.34 \\
9 & 3 & 876.41 & -9.24 & 1124.07 & -6.65 \\
10 & 1 & 1696.23 & -20.64 & 2186.11 & -14.49 \\
\hline
\end{tabular}

respectively. Global energy predictions for pozapanib, sorafenib and axitinib with VEGF complex were reported in Tables 1, 2 and 3 respectively.

Pazopanib docked with VEGF is shown in Figure 3a. Hydrogen bonding and steric interactions were observed in pozapanib ligand map (Figure $3 b)$. Hydrogen bonding occurred with $\mathrm{HOH}$ 176(B), $\mathrm{HOH}$ 147(B), $\mathrm{HOH} 153(\mathrm{~B})$, $\mathrm{HOH} 126(\mathrm{~B}), \mathrm{HOH} 138(\mathrm{~B})$ and Glu $30(\mathrm{~B})$. The strength of the bonds are $-2.50,-1.40,-2.50,-1.79,-2.50,-1.89$ and $1.12 \mathrm{Kcal} / \mathrm{mol}$ respectively. These interactions were quite favourable due to negative free energy and suitable bond lengths. Steric interactions occurred with Leu 32(A), Ile 29(A), Thr 31(B), Gly 58(B), Gly 59(B) and Cys 59(B). Global energy predictions for pozapanib - VEGF complex (Table 1) shown that the docking score ranked according to their global energy. The contributions of the van der Waals forces and atomic contact energy (ACE) to the global binding energy have been shown. The best binding energy (minimum energy) is $-19.15 \mathrm{Kcal} / \mathrm{mol}$. The negative value of the binding energy shows that the pozapanib can selectively inhibit VEGF. This is consistent with the work of Yadav et al. (2017).

Sorafenib docked with VEGF is shown in Figure 4a.
Hydrogen bonding and steric interactions were observed in sorafenib ligand map (Figure 4b). Hydrogen bonding occurred with $\mathrm{HOH} 177(\mathrm{~F}), \mathrm{HOH} 140(\mathrm{~F}), \mathrm{HOH} 166(\mathrm{~F})$, Lys 107(F), HOH 202(E), $\mathrm{HOH} 114(\mathrm{~F}), \mathrm{HOH} 140(\mathrm{E})$, and $\mathrm{HOH} 143(\mathrm{E})$. The strength of the bonds are $-2.50,-0.01$, $1.16,-0.56,-1.71,-1.26,-2.50$ and $-1.89 \mathrm{Kcal} / \mathrm{mol}$ respectively. These interactions were quite favorable due to negative free energy and suitable bond lengths. Steric interactions occurred with Thr 31(E), Thr 31(F) and Gln 89(H). Global energy predictions for Sorafenib - VEGF complex (Table 2) shown that the docking score has been ranked according to their global energy. The global energy is the binding energy of the solution. The contributions of the van der Waals forces and atomic contact energy (ACE) to the global binding energy is shown in Table 2 . The best binding energy (minimum energy) is $-22.48 \mathrm{Kcal} / \mathrm{mol}$. The negative value of the binding energy shows that the Sorafenib can selectively inhibit VEGF. This agreed with the report of Ahuja and Singh (2016) on in silico approach for SAR analysis of the predicted model of DEPDC1B: a vovel target for oral cancer.

Axitinib docked with VEGF is shown in Figure $5 a$. 
Table 3. Global energy predictions for axitinib - vascular endothelial growth factor (VEGF) complex.

\begin{tabular}{lccccc}
\hline Rank & Solution Number & $\begin{array}{c}\text { Global Energy } \\
\text { Kcal/mol }\end{array}$ & $\begin{array}{c}\text { Attractive VdW } \\
\text { Kcal/mol }\end{array}$ & $\begin{array}{c}\text { Repulsive VdW } \\
\text { Kcal/mol }\end{array}$ & ACE Kcal/mol \\
\hline 1 & 4 & -22.37 & -6.31 & 0.14 & -8.56 \\
2 & 5 & -17.76 & -12.19 & 8.51 & -5.00 \\
3 & 6 & -15.73 & -13.29 & 17.49 & -7.75 \\
4 & 2 & -2.17 & -2.08 & 1.86 & -0.77 \\
5 & 10 & 28.69 & -14.48 & 66.33 & -2.73 \\
6 & 8 & 212.41 & -16.71 & 312.77 & -9.26 \\
7 & 7 & 336.93 & -10.95 & 445.28 & -2.89 \\
8 & 1 & 363.44 & -19.02 & 507.20 & -9.43 \\
9 & 9 & 398.49 & -12.37 & 547.32 & -14.23 \\
10 & 3 & 635.06 & -18.61 & 855.72 & -14.24 \\
\hline
\end{tabular}

Hydrogen bonding and steric interactions were observed in sorafenib ligand map (Figure $5 b$ ). Hydrogen bonding occurred with Gly 65(G), $\mathrm{HOH} 126(\mathrm{~F}), \mathrm{HOH} 132(\mathrm{G}), \mathrm{HOH}$ 164(G) and Tyr 21(F). The strength of the bonds are $2.50,-1.48,-0.23,-2.50$ and $-2.50 \mathrm{Kcal} / \mathrm{mol}$ respectively. These interactions were quite favorable due to negative free energy and suitable bond lengths. Steric interactions occurred with Gln 89(E), His 90(E), Met 81(E), lle 83(E), Lys 48(E), Asp 63(G), Leu 66(G) and Tyr 21(F). Global energy predictions for axitinib - VEGF complex (Table 3) showed the docking score. The contributions of the van der Waals forces and atomic contact energy (ACE) to the global binding energy have been presented in Table 3 . The best binding energy (minimum energy) is -22.37 $\mathrm{Kcal} / \mathrm{mol}$. The negative value of the binding energy shows that the axitinib can selectively inhibit VEGF. This is consistent with our previous publication using Patchdock, a molecular docking algorithm based on shape complementarity principles (Ikpeazu et al., 2017)

\section{Conclusion}

The best binding energy (minimum energy) is -19.15 $\mathrm{Kcal} / \mathrm{mol}$, $-22.48 \mathrm{Kcal} / \mathrm{mol}$ and $-22.37 \mathrm{Kcal} / \mathrm{mol}$ for pozapanib, sorafenib and axitinib respectively. The negative value of the binding energy shows that pozapanib, sorafenib and axitinib can selectively inhibit VEGF. Molecular interaction was used in structure-based drug design to predict the binding energy and conformation of ligands complexed to target receptors. Molecular interaction can be seen as "lock-and key" theory of enzyme action. The receptor is seen as the lock while the ligand is the key. It tries to explain the best conformation of the ligand when it binds to the receptor. During molecular interaction, the ligand and the protein try to achieve the "best-fit".

\section{CONFLICT OF INTEREST}

The authors declare that they have no conflict of interest.

\section{ACKNOWLEDGMENT}

We are grateful for the research grant from Abia State Government, Nigeria.

\section{REFERENCE}

Advanced Chemistry Development

(2008) http://www.acdlabs.com.

Andrusier, N., Nussinov, R., \& Wolfson, H. J. (2007). FireDock: fast interaction refinement in molecular docking. Proteins, 69(1), 139-159.

Ahuja, P., \& Singh, K. (2016). In Silico Approach for SAR Analysis of the Predicted Model of DEPDC1B: A Novel Target for Oral Cancer. Advances in Bioinformatics, Pp. 1-8.

Escudier, B., Eisen, T., Stadler, W. M., Szczylik, C., Oudard, S., Siebels, M., Negrier, S., Chevreau, C., Solska, E., Desai, A. A., Rolland, F., Demkow, T., Hutson, T. E., Gore, M., Freeman, S., Schwartz, B., Shan, M., Simantov, R., \& Bukowski, R. M. (2007). Sorafenib in advanced clear-cell renal-cell carcinoma. New England Journal of Medicine. 356 (2), 125-34.

FDA (2007). FDA Approves Nexavar for Patients with Inoperable Liver Cancer, Press release.

Ikpeazu, O. V., Otuokere, I. E., \& Igwe, K.K. (2017). Computational Characterization of the Binding Energy and Interactions between Trimethoprim and Dihydrofolate Reductases of Candida albicans, Staphylococcus aureus and Thermotoga maritima. International Journal of Pharma and Drug Development, 2(2), 52-56.

Keating, G. M., \& Santoro, A. (2009). Sorafenib: a review of its use in advanced hepatocellular carcinoma. Drugs, 69(2), 22340.

Khurana, V., Minocha, M., Pal, D., \& Mitra, A. K. (2014). Inhibition of OATP-1B1 and OATP-1B3 by tyrosine kinase inhibitors. Drug Metabol Drug Interact. Pp. 1-11.

Mashiach, E., Schneidman-Duhovny, D., Andrusier, N., Nussinov, R., \& Wolfson, H. J. (2008). Fire Dock a web server for fast interaction refinement in molecular docking. Nucleic Acid Res., 36, 229-292.

Molegro Molecular Viewer (2012). Molegro - a CLC bio company Finlandsgade 10-12 8200 Aarhus N Denmark http://www.clcbio.com.

Nexavar (Sorafenib) dosing, indications, interactions, adverse 
effects, and more. Medscape Reference. WebMD. http://reference.medscape.com/drug/nexavar-sorafenib342260\#showall. Retrieved 26 December 2013.

Nexavar (Sorafenib) tablet, film coated [Bayer HealthCare Pharmaceuticals Inc.]. DailyMed. Bayer HealthCare Pharmaceuticals Inc. (2013).

Pick, A. M., \& Nystrom, K. K. (2012). Pazopanib for the treatment of metastatic renal cell carcinoma. Clinical Therapeutics. 34(3), 511-520.

Product Information Votrient® Tablets (2013). TGA eBusiness Services. GlaxoSmithKline Australia Pty Ltd. 25 (2013). https://www.ebs.tga.gov.au/ebs/picmi/picmirepository.nsf/pdf? OpenAgent\&id=CP-2010-PI-07077-3. Retrieved 27 January 2014.

Rini, B., Rixe, O., Bukowski, R., Michaelson, M. D., Wilding, G., Hudes, G., Bolte, O., Steinfeldt, H., Reich, S. D., \& Motzer, R. (2005). AG-013736, a multi-target tyrosine kinase receptor inhibitor, demonstrates anti-tumor activity in a Phase 2 study of cytokine-refractory, metastatic renal cell cancer (RCC). Journal of Clinical Oncology ASCO Annual Meeting Proceedings. 23(16S), 4509.

Rugo, H. S., Herbst, R. S., Liu, G., Park, J. W., Kies, M.S., Steinfeldt, H.M., Pithavala, Y. K., Reich, S. D., Freddo, J. L., \& Wilding, G. (2005). Phase I trial of the oral antiangiogenesis agent AG-013736 in patients with advanced solid tumors: pharmacokinetic and clinical results. Journal of Clinical Oncology, 23(24), 5474-83.

Schöffski, P (2012). Pazopanib in the treatment of soft tissue sarcoma. Expert Review of Anticancer Therapy. 12(6), 711723.
Smalley, K. S., Xiao, M., Villanueva, J., Nguyen, T. K., Flaherty, K. T., Letrero, R., Van Belle, P., Elder, D. E., Wang, Y., Nathanson, K. L., \& Herlyn, M. (2009). CRAF inhibition induces apoptosis in melanoma cells with non-V600E BRAF mutations. Oncogene. 28(1), 85-94.

Thompson, M. A. ArgusLab 4.0. (2007). Planaria Software LLC, Seattle, WA. http://www.arguslab.com.

Verweij, J., \& Sleijfer, S. (2013). Pazopanib, a new therapy for metastatic soft tissue sarcoma. Expert Opinion on Pharmacotherapy. 14(7), 929-935.

Wilmes, L. J., Pallavicini, M. G., Fleming, L. M., Gibbs, J., Wang, D., Li, K. L., Partridge, S. C., Henry, R. G., Shalinsky, D. R., Hu-Lowe, D., Park, J. W., McShane, T. M. Lu, Y., Brasch, R. C., \& Hylton, N. M. (2007). AG-013736, a novel inhibitor of VEGF receptor tyrosine kinases, inhibits breast cancer growth and decreases vascular permeability as detected by dynamic contrast-enhanced magnetic resonance imaging. Magnetic Resonance Imaging, 25(3), 319-27.

Yadav, S., Pandey, S. K., Singh, V. K., Goel, Y., Kumar, A., \& Singh, S.M. (2017) Molecular docking studies of 3bromopyruvate and its derivatives to metabolic regulatory enzymes: Implication in designing of novel anticancer therapeutic strategies. PLOS ONE, 12(5), e0176403.

Zivi, A., Cerbone, L., Recine, F., \& Sternberg, C. N. (2012). Safety and tolerability of pazopanib in the treatment of renal cell carcinoma. Expert Opinion on Drug Safety. 11(5), 851859. 